edema toward the termination of the disease. These findings were concurred in by Dr. Smith and Dr. J. H. Musser.

Examinations of Urine, Blood and Feces.-By Dr. George Morris Piersol. Urine: Amber, cloudy, flocculent, acid, 1.022; faint trace of albumin by Heller test and ferrocyanid test; faint trace of albumose; no sugar; excess of indican; no bile pigments; trace of urobilin; no acetone or diacetic acid. Microscopically there were many leukocytes and epithelial cells; no casts.

Blood: Hemoglobin 70 per cent. (Tallquist); $3,830,000$ erythrocytes; 7,200 leukocytes.

Feces: Thin, watery, light brown, offensive, faintly acid, hydrobilirubin, well-digested muscle fiber, no muscle nuclei, small amount vegetable fiber, much mucus and pus, no blood, occult blood or parasites. Further examination gave negative results.

Sputum: Negative for tubercle bacilli.

Necropsy.-This (by H. T. K.) was performed six hours after death. With the aid of the subsequent histologic examination, the following anatomic diagnoses have been made: Vesicular emphysema, healed tuberculosis, passive congestion of lungs; ehronic focal fibrous pericarditis; brown atrophy of heart, chronic interstitial myocarditis; sclerotic-aortic, mitral, tricuspid valvulitis; simple (non-Iuetic) arterioselerosis; perilobular fibrosis, passive congestion, fatty degeneration of liver; chronie fibrous cholecystitis, cholelithiasis (not demonstrably obstructive); chronic atrophic gastritis; chronic catarrhal enteritis; senile atrophy of spleen; chronic interstitial nephritis, nephrolithiasis, ehronic eatarrhal pyelitis; chronic interstitial pancreatitis with slight fat infiltration; endothelioma of omentum. The abdominal cavity contained about one liter of clear limpid yellow fluid; intestines were much distended with gas; transverse colon was markedly ptosed. The great omentum was densely adherent in the pelvic cavity and was diffusely thickened throughout its entire extent by the presence of a large number of spherical, generally discrete but sometimes confluent. mottled red, gray and purple, relatively firm nodules measuring from $3 \mathrm{~mm}$. to $15 \mathrm{~mm}$. in diameter, and averaging about $1 \mathrm{~cm}$. The omentum formed a flat mass measuring 17 by 14 by $2 \mathrm{~cm}$., and showing a smooth, glistening, transparent surface except where adherent to bladder, rectum and small intestine. The cut surface showed the nodules to be mottled red, purple and white, generally firm, slightly bulging, slightly bleeding, and with a few pin-headsized areas of necrosis. Extension of the process to the gastrocolic omentum, gastrosplenic ligament, to a slight degree to the small intestine and mesentery and to the colon, especially in the epiploic appendages, was noted.

Histologic Examination.-There is found a network of connective tissue, giving the tumor a somewhat alveolated appearance. This is richly vascularized and apparently serves as the basis for outgrowth of the cells into the spaces. They are arranged in chains and multiple layers. As a rule, there is extensive necrosis in the center of the alveoli, but in numerous fields the central areas are found to have thin-walled blood vessels from which the cells "comb out" in a typically sarcomatous fashion. The tumor cells are large, polygonal, rich in protoplasm and contain as a rule a single, large, vesicular round or oval nucleus. In some cases the nuclei are multiplied within a cell so as to overlap one another. Some few of the cells show apparent vacuolation of their protoplasm, which on more careful study is seen to be simply a lack of condensation in contrast with other areas of greater density.

The various features are illustrated in the accompanying drawings.

Diagnosis: Endothelioma of great omentum.

The Entry of Bacteria into the Lungs.-In a report made to the Philosophical Society, Cambridge, England, on experiments as to the entry of bacteria into the lungs (abstract in Nature, March 16). Drs. Cobbett and Graham-Smith announced that if $B$. prodigiosus were placed in the mouths of very young guinea-pigs it could be detected in the lungs examined a few minutes later. They assume that this affords an explanation of tuberculosis in animals fed with tubercle bacilli in many experiments, and invalidates certain conclusions which have been deduced as to the usual path of infection in this disease.

\section{A NEW AIR-WATER SPHYGMOMANOMETER}

\section{ARTHUR J. BENDICK, II.D. NEW YORK}

Realizing the excessive number of sphygmomanometers already on the market, I felt some trepidation in designing the sphygmomanometer to be described. It was only after I had convinced myself that the very multiplicity of types was due to their faults and limitations, that I had the present model constructed.

Sphygmomanometers are mainiy of two types: (1) the mercury manometers; (2) the spring manometers.

1. The disadvantage of the mercury manometer is chiefly the loss or distortion of the pulse-wave during transmission to the instrument. Either no pulsation is obtained, or at best there is a slow oscillation, entirely distorted in both character and duration by the inertia of the mercury. The truth of this statement can be readily proved by connecting rubber-tubing to the

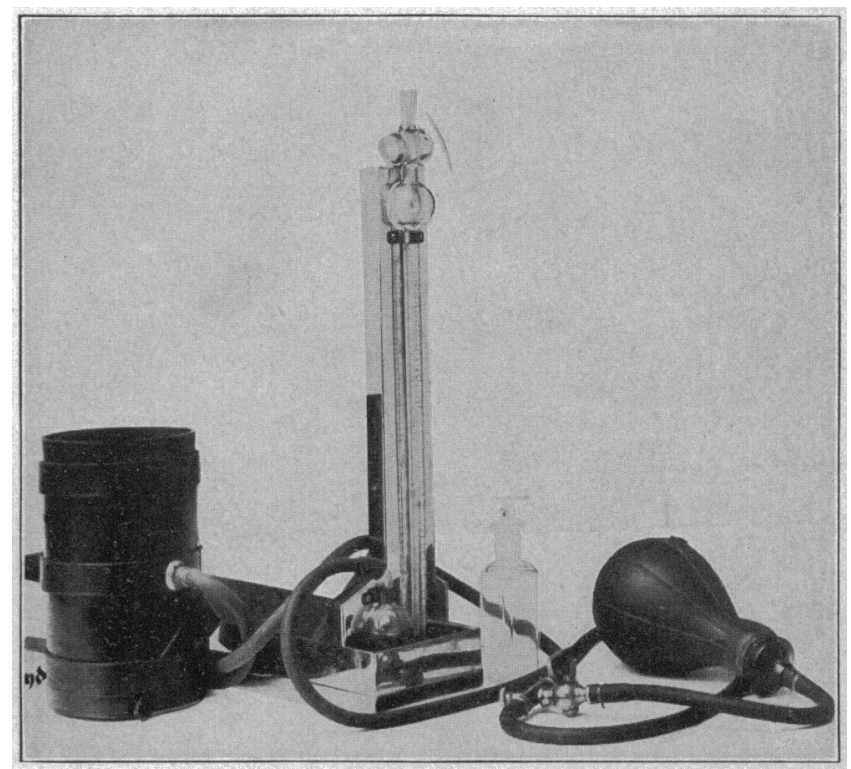

Fig. 1.-Photograph of the complete apparatus, showing tube, stand, cuff, lubber tubing and Politzer afr-bag which serves as a pump.

manometer and suddenly pinching it. The mercury will rise, then fall below its previous position, and will then oscillate for some time. A single impulse has been distorted by the instrument into a series of oscillations.

2. The spring manometers have not met with favor chiefly on account of their inaccuracy after prolonged use. The spring weakens with use and is also affected by temperature. Furthermore, the price of that class of spring manometers which can be used with accuracy for any reasonable length of time is prohibitive.

To avoid the inertia of the mercury one naturally turns to the lighter fluids, such as water, alcohol, benzin, etc. But to use these fluids alone a considerable quantity is required, which exerts as great inertia as the smaller quantity of the heavier liquid, mercury. Consequently, to use only a few cubic centimeters of these lighter fluids, we must use them working against some resistance. The simplest and most elastic resistance obtainable I believe to be air compression. This principlethe compression of an enclosed column of air by a few cubic centimeters of water-is utilized in my instrument.

A glass tube of the shape shown in Figure 2 is used. The tube is filled with water until the level indicated in the illustration is reached. The stop-cock is then closed and we have an enclosed column of air above the fluid. This column of ai: 
can be compressed by the fliid and the degree of compression can be ascertained from the scale. Pressure from the cuff is exerted on the fluid at $A$, which causes the fluid at $B$ to rise until the air-pressure in the tube $C$ is equal to the pressure in the cuff. This pressure may be then read off on the scale.

The bulb $A$ acts as a reservoir for the fluid, while the bulb $D$ acts as a reservoir for the compressed air, allowing the licuid to rise the entire length of the tube in recording pressures up to $300 \mathrm{~mm}$. of mercury. These two bulbs allow of the use of a larger and hence more accurate scale than if straight tubes were used.

The rest of the apparatus is as simple as possible.

1. The cuff consists of a cloth reenforced rubber bag $12 \mathrm{~cm}$. wide, closed by three rapid adjustable straps. A metal plug joins the bag with the rubber tubing.

2. The pump consists of an 8-ounce Politzer bag.

3. A metal "T" tube with stop-cock and needle-valve escape for gradually releasing the pressure. The stop-cock allows the air-pump to be disconnected, giving direct communication between the cuff and the instrument.

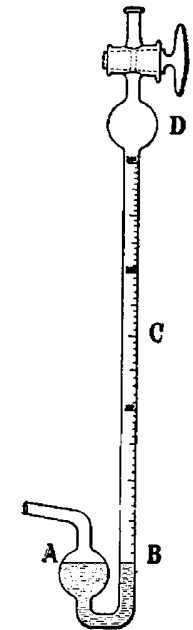

Fig. 2.-Diagram showing the glass tube of the water sphygmomanometer. A, bulb partially filled with water on which pressure is exerted by a column of air in the tube leading from the cuff. $B$, level of water in upright alibrated tube C, which contains air above. $D$, bulb in the tube $\mathrm{C}$ to contain the air as the wat e r rises. At the top of the tube is a cock for closing the tube after the water is put in below.

103 West Eighty-First Street.

Heredity, Growth and Decay.- - Heredity is a reality, but is not so definite or so mechanical as is generally supposed. Nutrition is responsible for much that passes for heredity. Only after its effects have been definitely ascertained can the real mechanism of heredity be understood. Why, for example, does each organism reach maturity and finally sink into old age? Is there a determent in the germ cell that when active checks growth? Does the mechanism of life run progressively to a certain point and then refuse to act? Or is maturity merely a state of maximum nutrition and old age a running down because nutrition fails? To state the problem in another way: Does a given organ cease to grow because the possibilities of its inherited mechanism have become exhausted, or does growth end because nutrition fails when the energy of the organism is turned in other directions? The latter is, I believe, the sounder view." (From Patten's "The Social Basis of Religion," New York, 1911.)

\section{THE COMBINED LSE OF TENTS AND INTRA-CTERINE MEDICATION}

\section{E. C. DLDILY, M.D. \\ CHICAGO}

Dilatation of the uterus by means of tents and treatment by intra-uterine applications made up a very large part of the gynecologic therapeutics of a former generation. Both of these measures have fallen into almost universal disuse; the tent, although of great diagnostic and therapeutic value, having been discarded because of the frequent disabling, not to say, fatal metritis, salpingitis, and peritonitis, which, even under the most careful and judicial handling, occasionally followed its use. The old routine intra-uterine applications as used in the office or in the patient's house were cond e m n e d, not only because they were generally useless, but also and more especially because they were dangerous and sometimes destructive. Since these measures have been relegated to the dark ages of gynecology, we have for the most part put in place of them forcible dilatation by means of steel instruments, and curettage under anesthesia. Forcible dilatation popularized by our late fellow, Goodell, and others, undoubtedly has wide usefulness when used with care and judgment. Even in the hands of the incompetent and careless practitioner it will be less hazardous than the old routine treatment, because it

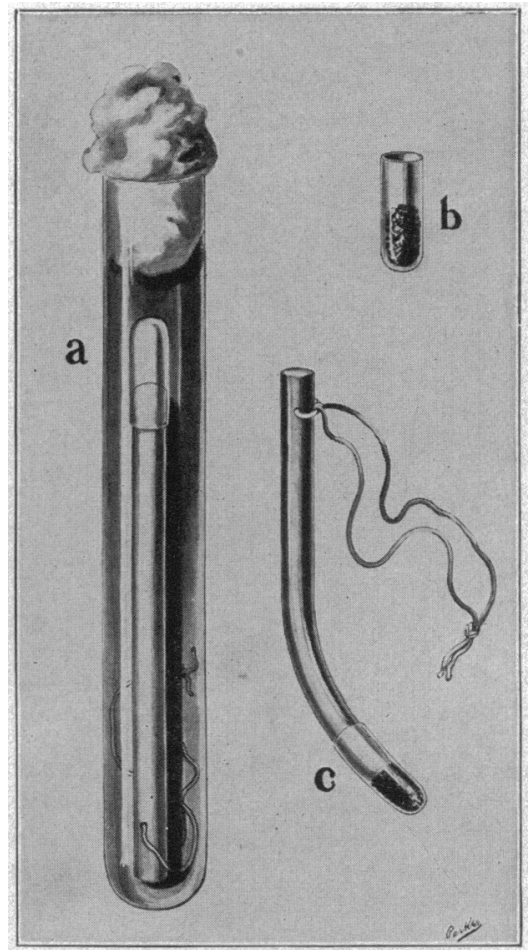

Device for prolonged dilatation of the uterus in conjunction with thorough intra-uterine medication: $a, a$ tupelo tent with gelatin half-capsule attached half-capsule, containing two parts of potassium lodid and one part of iodin crystals; $c$, a curved tent on the distal end of which has been placed the halfcapsule containing iodin one part and potassium iodid two parts, this being soluble in water. kept sterile in a test-tube; $b$, a gelatin

rises to the dignity of a surgical operation and is, therefore, presumably always undertaken with aseptic conditions and because it is not so frequently repeated. Forcible dilatation is transient in its effect, and, therefore, not always adequate; furthermore, if carried far enough to permit intra-uterine digital touch, which is often desirable, serious rupture of the uterus might result. The intra-uterine application of iodin or other substances usually, since it does not reach thoroughly the uterine mucosa, especially the uterine glands, gives disappointing results. Any measure, therefore, that will safely prolong the dilatation and bring the application effectively in contact with the mucosa and muciparous glands should be of value.

The sole purpose of this paper is to describe a simple means which has the double purpose of relatively safe prolonged dilatation of the uterus by means of tents and 